\title{
Characterization of Bimetallic Systems with UPS and PAX: Gold on Platinum and Palladium Surfaces
}

\author{
M. Moors ${ }^{a, *}$, T. Kobiela ${ }^{b}$, A. Krupski ${ }^{c}, \mathrm{C}$ BeCKeR $^{a}$ \\ AND K. WANDELT ${ }^{a}$ \\ ${ }^{a}$ Institute of Physical and Theoretical Chemistry, University of Bonn \\ Wegelerstr. 12, D-53115 Bonn, Germany \\ ${ }^{b}$ Faculty of Chemistry, Warsaw University of Technology \\ Noakowskiego 3, 00-664 Warsaw, Poland \\ ${ }^{c}$ Institute of Experimental Physics, University of Wrocław \\ pl. Maxa Borna 9, 50-204 Wrocław, Poland
}

In the present study the thermal behavior of ultrathin $\mathrm{Au}$ films deposited on different noble metal single crystal surfaces was studied by means of ultraviolet photoelectron spectroscopy and photoemission of adsorbed xenon. The primary goal of this work was to demonstrate the power of photoemission of adsorbed xenon as an easy to handle and very surface sensitive technique for the characterization of multi-component systems. All investigated systems, $\mathrm{Au}-\mathrm{Pt}(111), \mathrm{Au}-\mathrm{Pd}(111)$ and $\mathrm{Au}-\mathrm{Pd}(110)$ show a particular dependence of their electronic and structural properties on the annealing temperature. Au multilayer films with a thickness of 3 monolayer prepared at $150 \mathrm{~K}$ undergo in all cases a smoothening by annealing up to room temperature. While on $\mathrm{Pd}$ this effect is mainly detectable on the topmost atomic layer the ordering process on $\mathrm{Pt}$ is also affecting the deeper layers. Further annealing of the $\mathrm{Au}-\mathrm{Pd}$ system to $450 \mathrm{~K}$ and the $\mathrm{Au}-\mathrm{Pt}$ system to $750 \mathrm{~K}$, respectively, results in the onset of the alloying process at the interface between metal film and substrate. After annealing to 650 and $950 \mathrm{~K}$, respectively, the alloying finally extends to the very surface. The complete loss of $\mathrm{Au}$ from the surface can be detected at $1050 \mathrm{~K}$ on Pd and at $1150 \mathrm{~K}$ on Pt. The orientation of the substrate has only a weak influence, showing up e.g. in additional electronic states of the not alloyed $\mathrm{Au}-\mathrm{Pd}(111)$ and $\mathrm{Au}-\mathrm{Pd}(111)$ systems. Adsorption of $\mathrm{CO}$ as a probe molecule illustrates the formation of different adsorption sites on the bimetallic systems during the Au diffusion process.

PACS numbers: 79.60.Bm, 73.61.At, 71.20.Be, 71.20.Eh, 71.20.Gj

*corresponding author; e-mail: moors@pc.uni-bonn.de 


\section{Introduction}

The study of single crystal metal alloy surfaces has always been of great interest. Such multi-component systems often not only provide good model systems for heterogeneous catalysts [1] but also play a vital role in emerging new technologies relevant for environmental and energy-related applications, such as fuel cells [2].

In this work we focus on the behavior of ultrathin Au films deposited on different Pt and Pd single crystal surfaces. For a long time $\mathrm{Au}$ has been regarded as the least reactive metal for catalytic reactions, but during the last years this opinion has changed considerably [3]. Highly dispersed $\mathrm{Au}$ deposited on a metal substrate exhibits a surprisingly high catalytic activity for several reactions even at low temperatures (e.g. CO oxidation) [4]. Recently it has been reported that the reactivity strongly depends on the preparation conditions and the resulting size of the Au nanostructures [5]. The substrate metals used here differ significantly in their chemical reactivity, e.g. on Pd catalysts the partial hydrogenation of butadiene to 1-butene is possible whereas on $\mathrm{Pt}$ only a dehydrogenation of the butadiene is found [6]. The combination of substrates possessing such different chemical properties with another chemically less active metal like Au may lead to interesting new alloy catalysts.

Our main investigation method was ultraviolet photoelectron spectroscopy (UPS), because it provides an easy access to the electronic structure of bimetallic systems. However, UPS also has one indisputable disadvantage. Due to the penetration depth of the UV radiation and the emission depth of the excited photoelectrons of up to several $\mathrm{nm}$ depending on their kinetic energy the obtained spectra always carry information also from subsurface layers. In order to get reliable information about the topmost atomic layer only the photoemission of adsorbed xenon (PAX) proved to be very suited. This method uses Xe atoms as probes, whose photoemission behavior is a direct indicator for the nature of their immediate adsorption site. The power of the PAX method as a technique for surface studies is based on the invariance of the binding energies of the $\mathrm{Xe} 5 p_{1 / 2}$ photoelectrons with respect to the vacuum level which is due to the weak interaction of Xe with surfaces and its rather large atomic diameter $(\approx 4.5 \AA)[7]$. This results in a high sensitivity of PAX to local differences in the work function of a heterogeneous surface. In contrast to regular UPS experiments the PAX spectra are only affected by the topmost substrate layer. But the greatest advantage of PAX is probably the fact that - apart from facilities for cooling the surface to $\approx 60 \mathrm{~K}-$ no additional equipment is needed. The occupation of different sites on heterogeneous surfaces leads to a superposition of the Xe $5 p$ spectra, shifted by the corresponding differences in the "local work function" [8]. This makes the PAX method an interesting alternative for the morphological and chemical characterization of multi-component systems such as bimetallic surfaces 
[9-12] and alloys [13-18]. In this work the authors want to demonstrate that the method is also very suitable for the systems $\mathrm{Au}$ on $\mathrm{Pt}$ and $\mathrm{Au}$ on $\mathrm{Pd}$.

\section{Experimental}

The vacuum system used for the UPS and PAX experiments consisted of a stainless steel vessel, equipped with a CMA-Auger electron spectrometer, a three grid LEED optics, a quadrupole mass spectrometer, a sputter gun and a helium resonance lamp together with a hemispherical electron energy analyzer to record $\mathrm{He}(\mathrm{I})$ and $\mathrm{He}(\mathrm{II})$ excited UV photoelectron spectra. The sample holder enabled a tilt of the sample about an axis parallel to the sample's surface as well as direct heating to $1200 \mathrm{~K}$ and cooling down to $60 \mathrm{~K}$ by a closed-cycle two-stage He-refrigerator. The sample temperature was measured by a $\mathrm{NiCr}-\mathrm{Ni}$ thermocouple. The $\operatorname{Pt}(111)$ surface was cleaned by repeated cycles of sputtering with $3 \mathrm{keV}$ argon ions at $300 \mathrm{~K}$ followed by annealing to $1100 \mathrm{~K}$. After the annealing process the residual carbon was removed in $7.0 \times 10^{-4} \mathrm{~Pa}$ of oxygen at the same temperature, followed by desorption of any remaining oxygen at $1200 \mathrm{~K}$. For the $\operatorname{Pd}(110)$ and $\operatorname{Pd}(111)$ surface this procedure had to be slightly modified. Oxidizing the residual carbon was performed at $750 \mathrm{~K}$, followed by oxygen desorption at $1100 \mathrm{~K}$. The deposition of gold was achieved by evaporation from a Knudsen cell. This cell had been constructed from an $\mathrm{Al}_{2} \mathrm{O}_{3}$ crucible with a diameter of $5 \mathrm{~mm}$. It was filled with a gold wire and closed by a 2-hole ceramic. The Knudsen cell was heated by a tungsten wire (diameter $0.3 \mathrm{~mm}$ ) wound around the crucible and thermally shielded by a water-cooled jacket. In order to control the deposition time a rotatable shutter was placed in front of the cell opening. The base pressure after bake out reached the $1.0 \times 10^{-8} \mathrm{~Pa}$ range, while the working pressure during $\mathrm{Au}$ deposition was below $1.0 \times 10^{-7} \mathrm{~Pa}$. The Au deposition rate was determined by work function measurements and adjusted to $0.5 \mathrm{ML} \mathrm{min}^{-1}(\mathrm{ML}=$ monolayer).

\section{Results and discussion}

$$
\text { 3.1. Au on Pt(111) }
$$

In order to study the electronic and morphologic properties of the system $\mathrm{Au}$ on Pt a $3 \mathrm{ML}$ thick Au film was prepared at a sample temperature of $150 \mathrm{~K}$ on a clean Pt(111) surface and annealed stepwise to $1150 \mathrm{~K}$. The measured He(II) excited UPS spectra $(h \nu=40.8 \mathrm{eV})$ of the successively annealed Au-Pt sample are displayed in Fig. 1a. In the binding energy range between 2 and $8 \mathrm{eV}$ below the Fermi energy $\left(E_{\mathrm{F}}\right)$ an $\mathrm{Au} 5 d$-derived signal intensity can be detected on the freshly prepared surface. In the further discussion we will mainly concentrate on the most intense peak at $6.0 \mathrm{eV}$ (peak A). Former studies by Salmeron et al. [19] and Kobiela et al. [20] on different Pt surfaces, by Moors et al. [21] on $\operatorname{Pd}(110)$ and by Citrin and Wertheim [22] on a glass substrate showed that, independent of the used substrate, the position of this peak (stemming from the $\mathrm{Au} 5 d_{3 / 2}$-derived subband) is stable at mono- and multilayer coverage. However, 

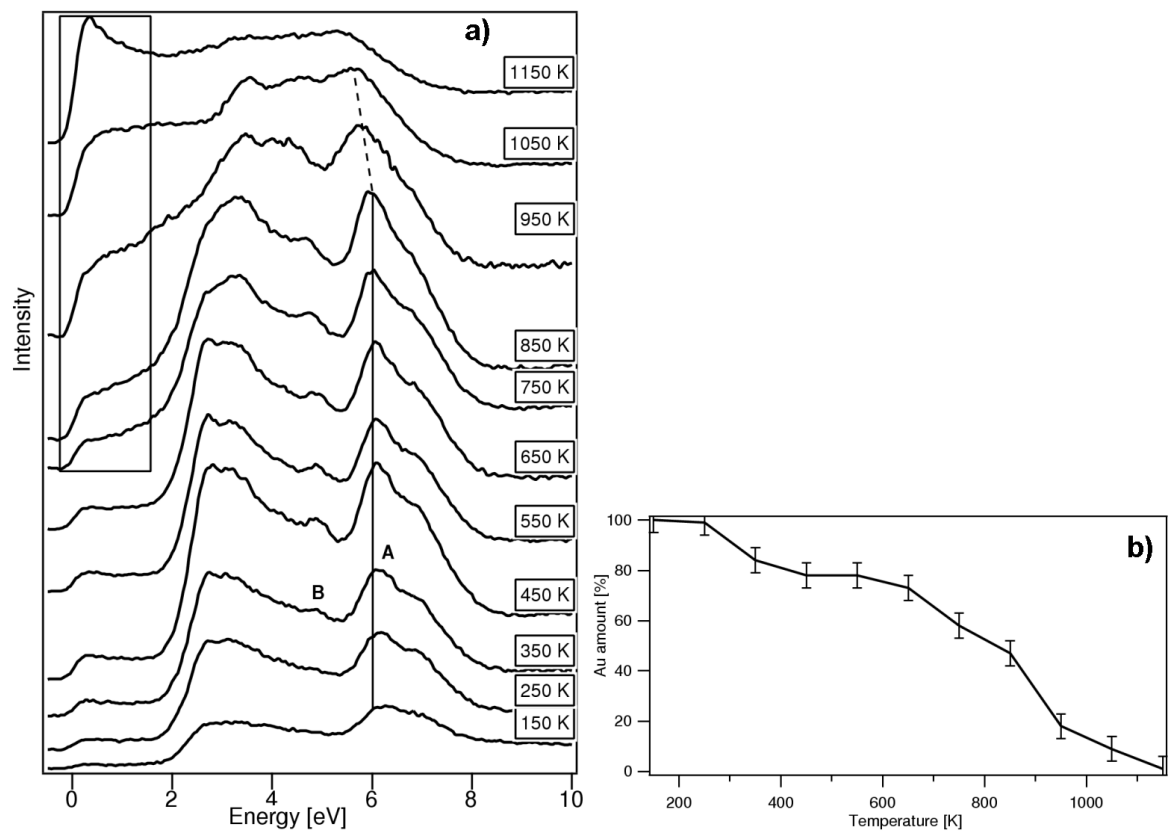

Fig. 1. (a) UPS spectra (He(II) radiation: $h \nu=40.8 \mathrm{eV}$ ) of a $3 \mathrm{ML}$ thick $\mathrm{Au}$ film deposited on $\mathrm{Pt}(111)$ at $150 \mathrm{~K}$ and annealed to the indicated temperatures for $5 \mathrm{~min}$. The development of the Pt related intensity and the characteristic Au peak are indicated by a box and a line, respectively. (b) Relative intensity of Au $5 d$ band related peaks as a function of annealing temperature.

a characteristic shift to lower binding energy has been found for submonolayer coverages. Consequently, this peak can also be used as an indicator for $\mathrm{Au}$ in the topmost surface layer for Au alloys. Annealing the freshly prepared Au film up to $350 \mathrm{~K}$ on the one hand results in an obvious decrease in the peak width and, on the other hand, in the appearance of an additional peak at $4.9 \mathrm{eV}$ (peak B), which was not detectable at lower temperatures. It corresponds to a peak calculated in the bulk density of states (DOS) of Au [22]. The position of this peak is stable up to an annealing temperature of $750 \mathrm{~K}$. These two observations can be related to a smoothening and ordering of the Au film. The film growth of $\mathrm{Au}$ at $150 \mathrm{~K}$ or below is characterized by a "hit and stick" mechanism [23] leading to a quite rough surface with many defects. With increasing temperature the previously disordered $\mathrm{Au}$ atoms become mobile resulting in a more compact film structure and flattened surface morphology. At an annealing temperature of $850 \mathrm{~K}$ a decrease in the intensity of peak $\mathrm{B}$ and a shift to lower binding energy to a final value of $4.4 \mathrm{eV}$ is observed. At the same time the intensity of all $\mathrm{Au} 5 d$ band related peaks starts to decrease and the previously discussed peak $\mathrm{A}$ at $6.0 \mathrm{eV}$ also starts to shift to lower binding energy. This is taken as a clear indication that Au is 
diffusing into the Pt bulk at this temperature. The diffusion process finally results in a reduced coordination number of $\mathrm{Au}$ atoms on the surface, which leads to a narrowing of the Au valence band. The width of the valence $d$-band spectra taken at temperatures of $950 \mathrm{~K}$ and above is significantly smaller than that up to $850 \mathrm{~K}$. It has been reported [24] that heating Au-covered Pt specimen to temperatures above $800 \mathrm{~K}$ causes rapid disappearance of $\mathrm{Au}$ from the surface region, and it was concluded that the Au adlayer starts to dissolve in the bulk of the Pt crystal at these temperatures. In contrast to these results, an $\mathrm{Au}$ fraction is still visible in our UPS spectra after annealing even up to $1050 \mathrm{~K}$. On the other hand, it is interesting to note that even before the onset of the Au decrease is visible additional electron density near the Fermi edge starts to appear in the $750 \mathrm{~K}$ spectrum, which must be related to $\mathrm{Pt}$. This may indicate the beginning of an intermixing process at the $\mathrm{Au}-\mathrm{Pt}$ interface already at this temperature. Alternatively, it cannot be completely excluded that the appearance of this peak at such a relatively low temperature is just the result of a more flattened, and because of this, also more uniform $\mathrm{Au}$ film on the Pt surface. Due to the finite information depth of regular UPS spectra it is certainly not possible with this technique to determine exactly when $\mathrm{Pt}$ atoms finally reach the outermost surface.

It has been found [25] that the calculated mixing enthalpy in the $\mathrm{Au}-\mathrm{Pt}$ system is positive, in complete agreement with the existence of a miscibility gap in the phase diagram of these alloys. This also means that the alloy components tend to be surrounded by atoms of their own kind. Furthermore, a very strong $\mathrm{Au}$ segregation has been found in the Au-Pt system [25]. This means that Au tends to cover the surface of these alloys even at low concentration. Therefore, the $\mathrm{Pt}$ related peak intensity near the Fermi edge more likely originates from subsurface $\mathrm{Pt}$ rather than from $\mathrm{Pt}$ patches in the topmost surface layer.

In order to reach more quantitative information about the $\mathrm{Au}$ amount of the very surface after annealing to different temperatures the integrated peak intensity (Fig. 1b) of the background subtracted $\mathrm{Au} 5 d$ band related peaks was calculated. Annealing the freshly prepared surface to room temperature already results in a significant decrease in the Au related signal intensity. This initial decrease can obviously not be caused by a removal of $\mathrm{Au}$ atoms from the surface. The increased mobility of the $\mathrm{Au}$ atoms at these temperatures leads to the formation of a more uniform $\mathrm{Au}$ layer and a concomitant reduction of the peak intensity. The next significant decrease above $650 \mathrm{~K}$ can more likely be interpreted with the onset of the $\mathrm{Au}$ diffusion into the Pt bulk. This is in good agreement with the previously discussed increase in the Pt related peak intensity near the Fermi edge. Between 850 and $950 \mathrm{~K}$ the process of Au depletion is accelerated whereas the remaining $\mathrm{Au}$ atoms above $950 \mathrm{~K}$ seem to be more resistant against inward diffusion. One explanation of this interesting behavior could be the formation of a quite stable $\mathrm{Au}-\mathrm{Pt}$ surface alloy. Only at $1150 \mathrm{~K}$ the Au related peak intensity is negligible, which is clear evidence that the diffusion process is completed at this temperature. 


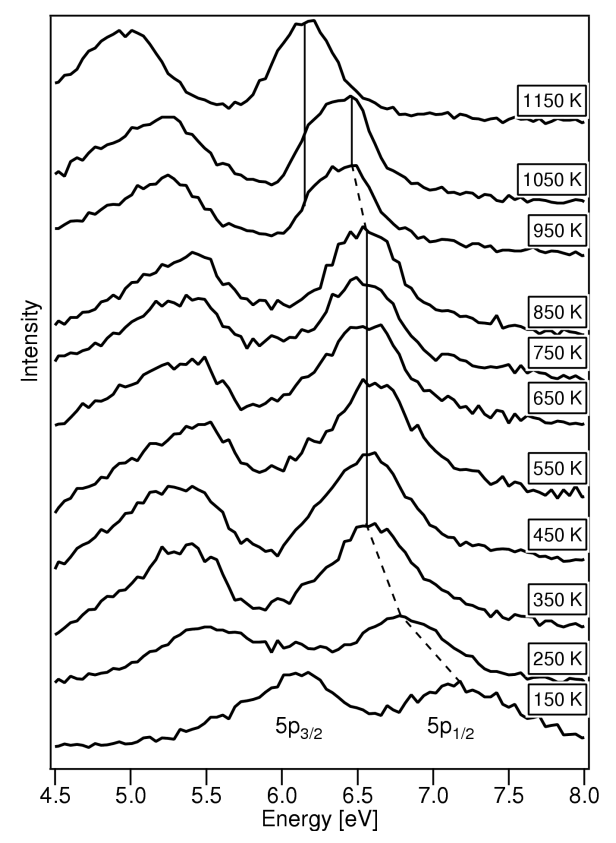

Fig. 2. UPS spectra (He(I) radiation: $h \nu=21.2 \mathrm{eV}$ ) of Xe-covered Au films deposited on $\mathrm{Pt}(111)$ at $150 \mathrm{~K}$ and annealed up to the given temperatures for $5 \mathrm{~min}$ in each case. In all cases $5 \mathrm{~L}$ Xe were adsorbed. Lines indicate the different Xe species.

As already mentioned above, regular UPS is not suited to give information about the topmost atomic layer only. Therefore, we used the perfectly surface sensitive PAX technique. Performing He(I) excited UPS spectra $(h \nu=21.2 \mathrm{eV})$ on a homogeneous surface covered with Xe atoms results usually in two additional Xe related peaks which can be assigned to the $5 p_{3 / 2}$ and the $5 p_{1 / 2}$ electronic states of adsorbed Xe. Due to the fact that the Xe $5 p_{3 / 2}$ peak at lower binding energy is composed of two peaks with different magnetic quantum numbers [26], it is decidedly broader than the Xe $5 p_{1 / 2}$ peak, so that we will focus in our further investigations only on the narrower $5 p_{1 / 2}$ peak. Figure 2 shows the background subtracted PAX spectra of a freshly prepared Au multilayer on $\mathrm{Pt}(111)(150 \mathrm{~K})$, which was annealed stepwise to $1150 \mathrm{~K}$. The Xe exposure was $5 \mathrm{~L}$ in all cases and the exposure was performed below $80 \mathrm{~K}$. On the at $150 \mathrm{~K}$ freshly prepared $\mathrm{Au}-\mathrm{Pt}$ surface a rather broad Xe $5 p_{1 / 2}$ peak is found at a relative high binding energy of $7.2 \mathrm{eV}$. After annealing to increasingly higher temperature this peak shifts to lower energy down to a final value of $6.6 \mathrm{eV}$ after annealing to $350 \mathrm{~K}$. Furthermore, the peak is now obviously narrower and more intense. This behavior is typical of a decrease in the surface roughness with increasing temperature caused by a higher lateral mobility of the Au atoms. The reduction of surface defects like step edges, adatoms and vacancies results in a higher population of $\mathrm{Xe}$ on flat $\mathrm{Au}$ terraces 
sites. Between 350 and $850 \mathrm{~K}$ the energy and the shape of the Xe $5 p_{1 / 2}$ peaks remain constant. Annealing to even higher temperatures results in another peak shift towards lower binding energy, reaching a final value of $6.2 \mathrm{eV}$ at $1150 \mathrm{~K}$, which matches perfectly the Xe $5 p_{1 / 2}$ position on a clean $\mathrm{Pt}(111)$ surface [27]. By analyzing the $\mathrm{Xe} 5 p_{1 / 2}$ peak at 950 and $1050 \mathrm{~K}$ in greater detail a clearly visible asymmetry can be recognized. This is actually due to a superposition of two peaks, one with lower intensity at $6.2 \mathrm{eV}$ and another one near $6.4 \mathrm{eV}$. The first one can be assigned to Xe atoms adsorbed on bare Pt, but the second one cannot be related to $\mathrm{Xe}$ on bare $\mathrm{Au}$. The clearly detectable difference of $\approx 0.2 \mathrm{eV}$ in comparison with the peak assigned to $\mathrm{Au}$ in the spectra between $450 \mathrm{~K}$ and $850 \mathrm{~K}$ shows a change of the "local work function" on the Au atoms, indicating their rearrangement on the surface. Therefore, this shift of $\approx 0.2 \mathrm{eV}$ can be interpreted as an evidence for the formation of an $\mathrm{Au}-\mathrm{Pt}$ surface alloy in the temperature range between 850 and $1050 \mathrm{~K}$. Annealing to even higher temperatures leads to a complete disappearance of $\mathrm{Au}$ atoms from the surface into the $\mathrm{Pt}$ bulk, resulting in only one $\mathrm{Xe} 5 p_{1 / 2}$ peak at $6.2 \mathrm{eV}$.

\subsection{Au on $P d(111)$}

The thermal behavior of Au films on a Pd substrate (especially concerning the diffusion process) is expected to be quite different compared to Au on Pt. Au is known to form ordered alloys with Pd already at moderate temperatures [28]. In contrast to the system $\mathrm{Au}-\mathrm{Pt}$, the mixing enthalpy of $\mathrm{Au}$ and $\mathrm{Pd}$ is known to be negative [29]. Figure 3a shows a series of He(II) excited UPS spectra of a 3 ML thick Au film deposited on a $\mathrm{Pd}(111)$ single crystal surface at $150 \mathrm{~K}$, which was then annealed stepwise to $1050 \mathrm{~K}$. Due to the rather thick Au film the Au related peaks are not significantly affected by the Pd substrate and can still be found between 2 and $8 \mathrm{eV}$ binding energy. However, unlike on $\mathrm{Pt}(111)$ no apparent changes in the spectral shape or intensity can be observed between 250 and $350 \mathrm{~K}$, indicating a rather well-ordered surface structure already at low temperatures. Only between 150 and $250 \mathrm{~K}$ a slight change of the appearance of the $\mathrm{Au}$ "multilayer" peak at $6.0 \mathrm{eV}$ (peak A) is visible due to a decreasing surface roughness. At $550 \mathrm{~K}$ we observe again the emergence of the bulk Au peak at around $4.7 \mathrm{eV}$ (peak B), which shifts to lower binding energy with increasing temperature. At this temperature also the shifting of peak A starts, reaching a final value of $5.5 \mathrm{eV}$ at $950 \mathrm{~K}$ before disappearing at $1050 \mathrm{~K}$. As mentioned before, this behavior is a clear indication for the beginning Au diffusion into the $\mathrm{Pd}$ bulk. On closer inspection also the appearance of a peak at a binding energy of $1.2 \mathrm{eV}$ is detectable already after annealing the sample to $450 \mathrm{~K}$. This peak can clearly be assigned to $\mathrm{Pd}$, so that we assume that (as already observed on $\mathrm{Pt}$ ) the alloying process seems to start at the $\mathrm{Au}-\mathrm{Pd}$ interface already $200 \mathrm{~K}$ below the temperature for which a formation of a surface alloy in the topmost layer is detected. With further increasing temperature additional Pd related electron density near the Fermi edge can be detected. Finally, after annealing to $1050 \mathrm{~K}$ 


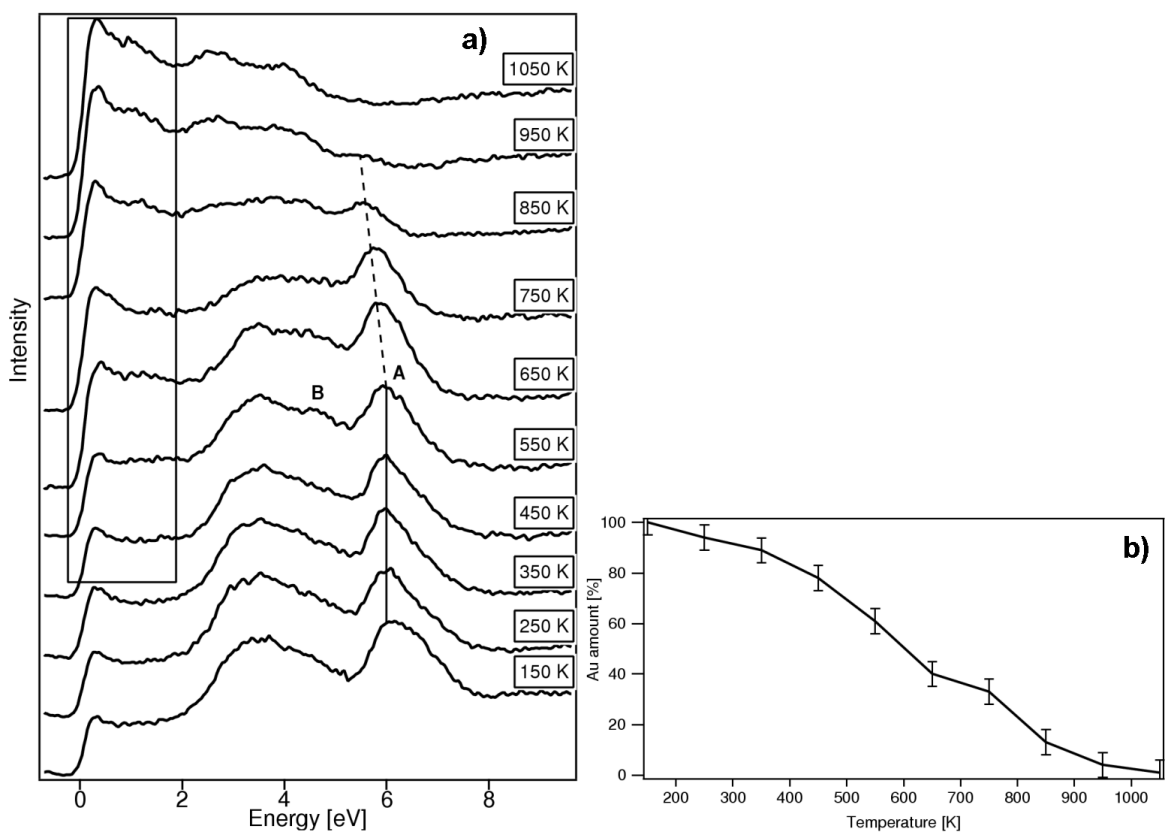

Fig. 3. (a) UPS spectra (He(II) radiation: $h \nu=40.8 \mathrm{eV}$ ) of a $3 \mathrm{ML}$ thick $\mathrm{Au}$ film deposited on $\operatorname{Pd}(111)$ at $150 \mathrm{~K}$ and annealed up to the given temperatures for $5 \mathrm{~min}$. The development of the Pd related intensity and the characteristic Au peak are indicated by a box and a line, respectively. (b) Relative intensity of Au $5 d$ band related peaks as a function of annealing temperature.

no Au related peaks are visible any more, indicating that all Au has diffused into the Pd bulk.

As already demonstrated with $\mathrm{Pt}$ the relative intensity of the $\mathrm{Au} 5 d$ band signals (after subtraction of the Pd background) is used as an indicator for the amount of Au within the information depth of the He(II) excited UPS spectra after annealing to different temperatures (Fig. 3b). This time we observe a decrease in the Au intensity already after annealing the sample to $250 \mathrm{~K}$, which also indicates that a smoothening of the $\mathrm{Au}$ film on Pd sets in already at lower temperatures than on Pt. Annealing the surface to $450 \mathrm{~K}$ results in a rapid intensity decrease, which proceeds up to $650 \mathrm{~K}$. We assume that this effect is primarily induced by the onset of the $\mathrm{Au}$ diffusion into the Pd bulk. Between 650 and $750 \mathrm{~K}$ the Au amount in the surface region remains nearly constant which may again be explained by the formation of a quite stable $\mathrm{Au}-\mathrm{Pd}$ surface alloy. Annealing to $850 \mathrm{~K}$ and above results in a fast $\mathrm{Au}$ depletion in the surface region. At $1050 \mathrm{~K}$ the measured $\mathrm{Au}$ signal intensity is negligible, proving that the Au diffusion process is completed. Although it is not possible by UPS only to determine exactly when Pd atoms finally reach the outermost atomic layer, we suggest that the first occurrence of 
the $\mathrm{Pd}$ peak at $1.2 \mathrm{eV}$, which is visible already at $450 \mathrm{~K}$ in Fig. 3a, is caused by the onset of the alloying process at the $\mathrm{Au}-\mathrm{Pd}$ interface while the main rise of $\mathrm{Pd}$ related intensity at $650 \mathrm{~K}$ in combination with the behavior of the Au peak at $6.0 \mathrm{eV}$ indicates that the alloying process has reached the very surface.

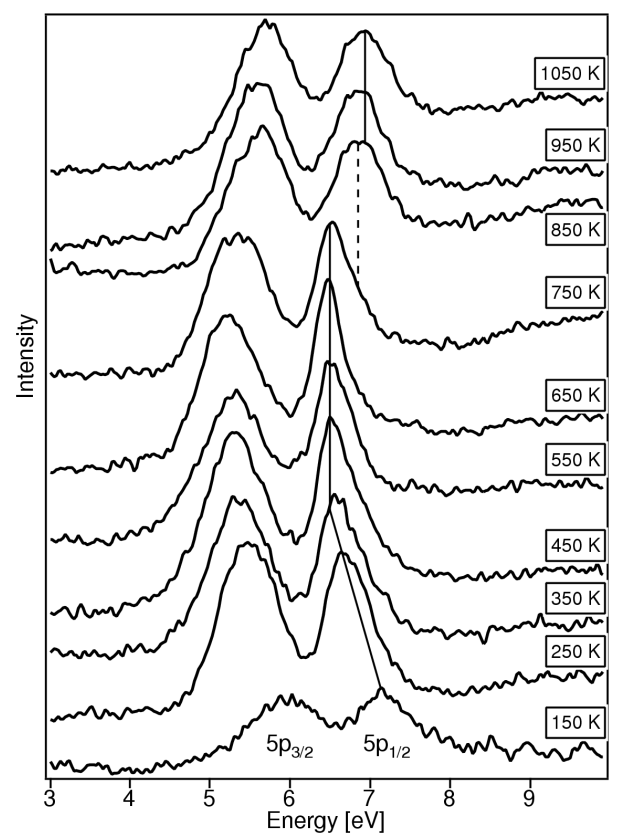

Fig. 4. UPS spectra (He(I) radiation: $h \nu=21.2 \mathrm{eV}$ ) of Xe-covered Au films deposited on $\operatorname{Pd}(111)$ at $150 \mathrm{~K}$ and annealed up to the given temperatures for $5 \mathrm{~min}$ in each case. All spectra except the Xe-covered clean $\mathrm{Pd}(111)$ are background subtracted. In all cases $5 \mathrm{~L}$ Xe were adsorbed. Lines indicate the different Xe species.

In order to verify this assumption we again consulted PAX spectra. For this purpose a $3 \mathrm{ML}$ thick Au film deposited on $\operatorname{Pd}(111)$ at $150 \mathrm{~K}$ was prepared and annealed stepwise to $1050 \mathrm{~K}$. Figure 4 shows the obtained PAX spectra after a Xe dose of $5 \mathrm{~L}$. Annealing the surface up to $350 \mathrm{~K}$ results in a continuous shift of the Xe $5 p_{1 / 2}$ peak to lower binding energy. As already observed on $\mathrm{Pt}$, this phenomenon can be explained by a smoothening of the Au film due to the increased mobility of the $\mathrm{Au}$ atoms with increasing temperature. Up to $650 \mathrm{~K}$ no further significant differences in the shape of the spectra can be detected. At $750 \mathrm{~K}$ the rise of a peak shoulder at around $6.8 \mathrm{eV}$ indicates the formation of an $\mathrm{Au}-\mathrm{Pd}$ surface alloy. The interpretation, however, is less conclusive than on $\mathrm{Pt}(111)$ (see above) because the binding energy of the $5 p_{1 / 2}$ peak of Xe adsorbed on pure $\operatorname{Pd}(111)$, which exists after annealing to $1050 \mathrm{~K}$ (see the He(II) excited UPS spectra in Fig. 3a) is nearly equal to the observed shoulder at $750 \mathrm{~K}$. Careful peak fitting (see Fig. 5) results in an energy difference of less than $0.1 \mathrm{eV}$. A binding energy of $6.9 \mathrm{eV}$ for the $\mathrm{Xe} 5 p_{1 / 2}$ 


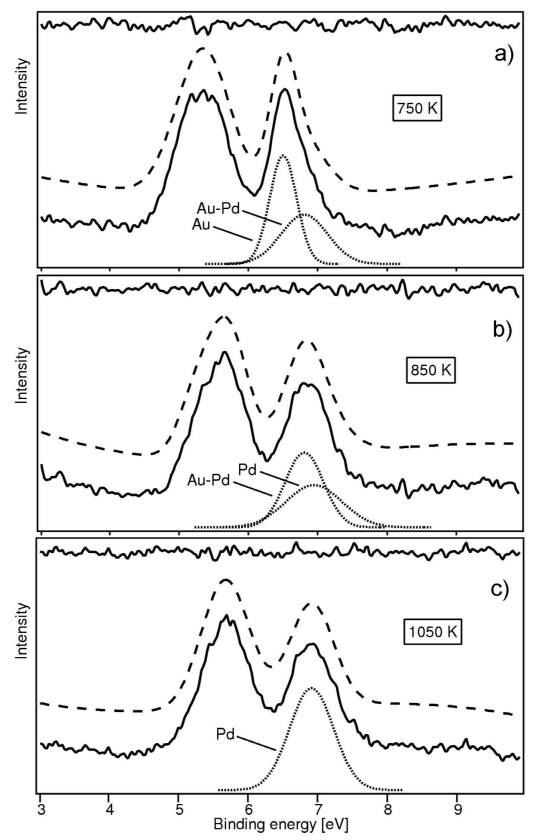

Fig. 5. UPS spectra (He(I) radiation: $h \nu=21.2 \mathrm{eV}$ ) of Xe-covered Au films deposited on $\mathrm{Pd}(111)$ at $150 \mathrm{~K}$ and annealed up to (a) $750 \mathrm{~K}$, (b) $850 \mathrm{~K}$ and (c) $1050 \mathrm{~K}$ for 5 min in each case. All spectra (black curves) are background subtracted. In all cases $5 \mathrm{~L} \mathrm{Xe}$ were adsorbed. Dotted curves show the numerical separation of the measured Xe $5 p_{1 / 2}$ orbital peaks and dashed curves - the best fit to the measured spectra. The residual intensities, i.e. the difference between measured and fit curve, are demonstrated by the upper difference traces.

peak after the final annealing step was also found on a freshly prepared $\operatorname{Pd}(111)$ surface, but to clearly distinguish between Xe adsorbed on a possible $\mathrm{Au}-\mathrm{Pd}$ alloy and Xe adsorbed on bare Pd patches a better energy resolution would be needed.

\section{3. $A$ u on $\operatorname{Pd}(110)$}

In order to verify that not only the substrate material but also its surface orientation has an influence on the alloying process we also investigated Au films on a $\mathrm{Pd}(110)$ single crystal surface. In Fig. 6a the He(II) excited photoemission spectra of a 3 ML thick Au film deposited on a clean $\mathrm{Pd}(110)$ surface at $150 \mathrm{~K}$, which has been annealed stepwise to a final temperature of $1050 \mathrm{~K}$, are displayed. As already observed on the $\mathrm{Pd}(111)$ sample annealing to $250 \mathrm{~K}$ results in a slight change of the appearance of the $\mathrm{Au}$ "multilayer" peak at $6.0 \mathrm{eV}$ (peak A) due to a decreasing surface roughness. Between 250 and $350 \mathrm{~K}$ no significant changes in the spectral shape or intensity are detectable. At $450 \mathrm{~K}$ a first increase in the $\mathrm{Pd}$ related intensity at $1.1 \mathrm{eV}$ can be observed. It is interesting to note that in contrast to the previously shown measurements on the substrates with (111) orientation no 

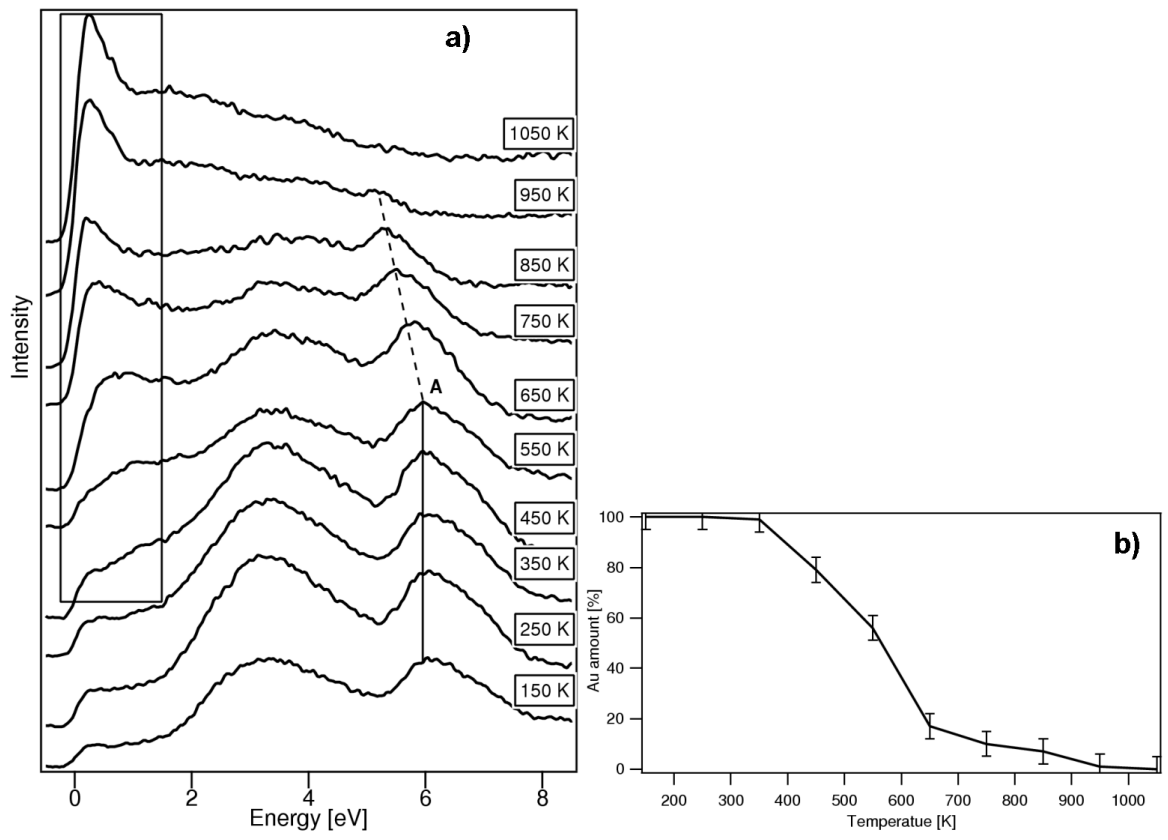

Fig. 6. (a) Summary of UPS spectra (He(II) radiation: $h \nu=40.8 \mathrm{eV}$ ) of a $3 \mathrm{ML}$ thick $\mathrm{Au}$ film deposited on $\mathrm{Pd}(110)$ at $150 \mathrm{~K}$ and annealed up to the given temperatures for 5 min in each case. The evolution of the Pd related intensity and the characteristic Au peak are indicated by a box and a line, respectively. (b) Relative intensity of $\mathrm{Au} 5 d$ band related peaks as a function of annealing temperature.

clear peak of the Au film can be found in the energy range between 4 and $5 \mathrm{eV}$. Thus, from this missing peak we may conclude that the substrate even at these relatively higher $\mathrm{Au}$ coverages has a noticeable influence on the electronic structure of the Au film. Former scanning tunneling microscopy (STM) studies by Kralj et al. [30] of this system showed that below a critical thickness of $2 \mathrm{ML}$ the Au film is still in registry with the $\mathrm{Pd}(110)$ substrate and, thus, strained. At higher coverage $\mathrm{Au}$ is forming a characteristic bulk-like $(1 \times 2)$ missing row reconstruction. Further annealing to $650 \mathrm{~K}$ again results in additional peak intensity near the Fermi edge (see Fig. 6a). At the same time peak A at $6.0 \mathrm{eV}$ starts to decrease in intensity and shifts to lower binding energy down to a final value of $5.3 \mathrm{eV}$ at $950 \mathrm{~K}$, indicating $\mathrm{Au}$ diffusion from the surface into the Pd bulk. After annealing to $1050 \mathrm{~K}$ no $\mathrm{Au}$ related intensity is detected any more, proving that the $\mathrm{Au}$ film has been completely dissolved in the Pd bulk.

Figure $6 \mathrm{~b}$ again displays the integrated $\mathrm{Au} 5 d$-band-related intensity of the UPS spectra as an indication for the Au amount in the surface region at different temperatures. In contrast to our observations on the $\operatorname{Pd}(111)$ sample no decrease in $\mathrm{Au}$ related intensity can be detected when annealing the sample up to room 
temperature. This indicates an even smoother Au overlayer on $\operatorname{Pd}(110)$ as compared to the Au film on $\mathrm{Pd}(111)$. Annealing the surface to $450 \mathrm{~K}$ leads to a strong decrease in the formerly stable peak intensity. This significant decrease in the Au signal proceeds up to $650 \mathrm{~K}$. The loss of more than $80 \%$ of the Au related signal from the near surface region in the temperature range between 450 and $650 \mathrm{~K}$ is a clear indication for $\mathrm{Au}$ diffusion into the $\mathrm{Pd}$ bulk. Above this temperature the residual peak intensity decreases slowly further up to $950 \mathrm{~K}$, where it vanishes completely. From these data it is possible to conclude that an $\mathrm{Au}-\mathrm{Pd}$ alloy is present in the temperature range from at least $\approx 450$ to $\approx 850 \mathrm{~K}$. In combination with the first occurrence of the $\mathrm{Pd}$ peak at $1.1 \mathrm{eV}$ visible at $450 \mathrm{~K}$ in Fig. 6a it can be suggested that the alloying at the $\mathrm{Au}-\mathrm{Pd}$ interface is starting at this temperature while at $650 \mathrm{~K}$ the process has reached the very surface.

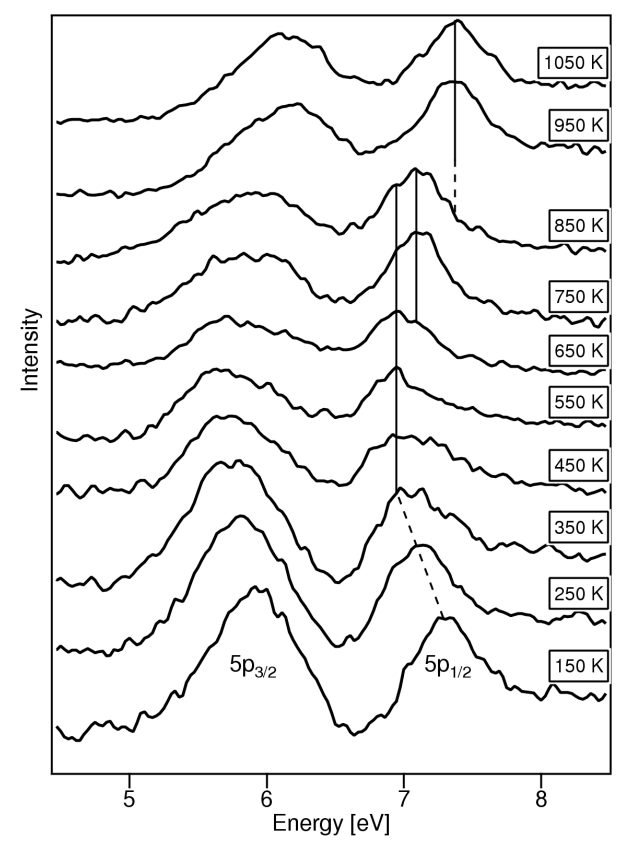

Fig. 7. Summary of UPS spectra (He(I) radiation: $h \nu=21.2 \mathrm{eV}$ ) of Xe-covered Au films deposited on $\mathrm{Pd}(110)$ at $150 \mathrm{~K}$ and annealed up to the given temperatures for 5 min in each case. All spectra except the Xe-covered clean $\operatorname{Pd}(110)$ are background subtracted. In all cases $5 \mathrm{~L}$ Xe were adsorbed. Lines indicate the different Xe species.

Figure 7 shows the background subtracted PAX spectra of a freshly at $150 \mathrm{~K}$ prepared and stepwise annealed $3 \mathrm{ML}$ thick $\mathrm{Au}$ film on $\mathrm{Pd}(110)$ with a total coverage of $5 \mathrm{~L} \mathrm{Xe.} \mathrm{Up} \mathrm{to} \mathrm{an} \mathrm{annealing} \mathrm{temperature} \mathrm{of} 350 \mathrm{~K}$ we can observe a continuous shift of the Xe $5 p_{1 / 2}$ peak towards lower binding energy. This effect, which was observed for all systems investigated, results from the smoothening of the topmost atomic layer with increasing temperature as already discussed pre- 
viously. Above $350 \mathrm{~K}$ the peak position remains stable at a binding energy of $6.9 \mathrm{eV}^{\dagger}$, but at $650 \mathrm{~K}$ the growth of a second $5 p_{1 / 2}$ peak at $7.1 \mathrm{eV}$ can be observed. This time, unlike to the PAX measurements on the (111) orientated Pd sample, the peak separation is clearly detectable. It is reasonable to assume that this new state can be assigned to Xe atoms adsorbed on an $\mathrm{Au}-\mathrm{Pd}$ surface alloy. The intensity of this peak reaches a maximum at $750 \mathrm{~K}$ indicating a maximal concentration of this alloy in the topmost atomic layer after annealing to this temperature. At $850 \mathrm{~K}$ a third Xe species can be detected at a $5 p_{1 / 2}$ peak energy of $7.3 \mathrm{eV}$. With further increasing annealing temperature this becomes the only remaining species on the surface, evidencing that the peak is due to Xe atoms adsorbed on pure $\mathrm{Pd}(110)$. Thus, the $\mathrm{PAX}$ measurements indicate the existence of an $\mathrm{Au}-\mathrm{Pd}$ surface alloy within a temperature range between 600 and $900 \mathrm{~K}$.

\subsection{CO adsorption on $\mathrm{Au}-\mathrm{Pd}$ systems}

In order to complement the PAX and UPS data obtained for $\mathrm{Au}$ on $\mathrm{Pd}(111)$ and $\mathrm{Pd}(110)$ we have used $\mathrm{CO}$ as a probe molecule. $\mathrm{CO}$ is an excellent candidate to probe the presence of $\mathrm{Pd}$ atoms at the very surface, because it is known to adsorb readily on $\mathrm{Pd}$ [33] but not on Au surfaces at moderate temperatures $[34,35]$. Therefore, we dosed $10 \mathrm{~L}$ of $\mathrm{CO}$ at room temperature on differently prepared $\mathrm{Au}-\mathrm{Pd}$ surfaces, which were produced by annealing a $3 \mathrm{ML}$ thick Au film on $\operatorname{Pd}(110)$ and $\mathrm{Pd}(111)$, respectively, to the temperatures indicated in Fig. 8. On $\mathrm{Au}-\mathrm{Pd}(110)$ (Fig. 8a) no $\mathrm{CO}$ related peaks can be detected in the $\mathrm{He}(\mathrm{II})$ excited UPS spectra up to an annealing temperature of $750 \mathrm{~K}$. At $850 \mathrm{~K}$ two peaks at 7.9 and $10.8 \mathrm{eV}$ become visible, which increase in intensity with further increasing annealing temperature. These peaks are in perfect agreement with the $5 \sigma / 1 \pi$ and $4 \sigma$ orbitals of CO molecules adsorbed on pure Pd [36] as well as with our conclusions from the PAX and UPS investigations on this surface. At room temperature CO is not able to adsorb neither on the Au covered surface nor on the $\mathrm{Au}-\mathrm{Pd}(110)$ surface alloy. Very interesting are the results from the same experiment on the $\mathrm{Au}-\mathrm{Pd}(111)$ system (Fig. 8b). As expected, no CO related peaks up to an annealing temperature of $650 \mathrm{~K}$ can be found, but at $750 \mathrm{~K}$ we observe already the appearance of peaks at 7.9 and $10.8 \mathrm{eV}$, which quickly gain in intensity with increasing annealing temperature. This is clear evidence that we have Pd atoms already at $750 \mathrm{~K}$ on the $\mathrm{Au}-\mathrm{Pd}(111)$ surface. With this knowledge the observed shoulder at $750 \mathrm{~K}$ in the PAX series (see Fig. 4) may also be explained with Xe adsorbed on $\mathrm{Pd}$ in the surface layer. However, we have to consider that in contrast to the results obtained on $\mathrm{Au}-\mathrm{Pt}(111)$ and $\mathrm{Au}-\mathrm{Pd}(110)$ we have no direct evidence from our adsorption experiments with $\mathrm{Xe}$ and $\mathrm{CO}$, whether a mixed $\mathrm{Au}-\mathrm{Pd}$ surface and/or small pure Pd patches are formed.

\footnotetext{
${ }^{\dagger}$ Due to a different and unfavorable detection geometry compared to the two other samples, $\mathrm{Pt}(111)$ and $\mathrm{Pd}(111)$, the energy scale for the $\mathrm{Xe}$ on $\mathrm{Au}-\mathrm{Pd}(110)$ spectra was reproducibly shifted towards lower energies by $\approx 0.4 \mathrm{eV}$. The binding energies in Fig. 7 have been corrected accordingly to match the Xe $5 p_{1 / 2}$ binding energy value at Xe monolayer coverage as known from the literature [31, 32].
} 


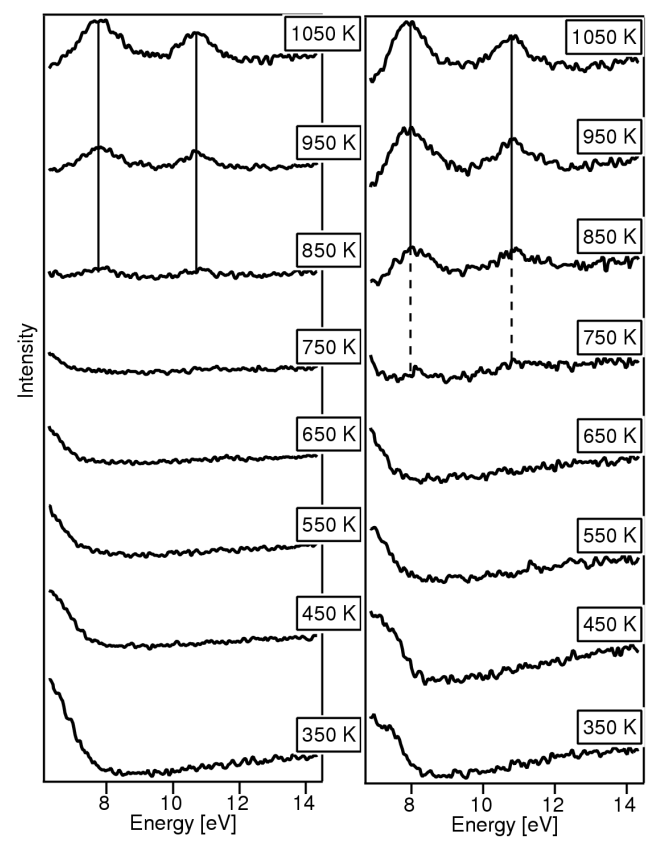

Fig. 8. Summary of UPS spectra (He(II) radiation: $h \nu=40.8 \mathrm{eV}$ ) of CO-covered $\mathrm{Au}$ films with a thickness of $3 \mathrm{ML}$ deposited on (a) $\mathrm{Pd}(110)$ and (b) $\mathrm{Pd}(111)$, respectively, at $150 \mathrm{~K}$ and annealed up to the given temperatures for $5 \mathrm{~min}$ in each case. In both cases $10 \mathrm{~L}$ of $\mathrm{CO}$ were allowed to adsorb at room temperature. Lines indicate the different $\mathrm{CO}$ orbital peaks.

\section{Conclusions}

All three investigated systems of 3 ML thick Au films on $\operatorname{Pt}(111), \operatorname{Pd}(111)$ and $\operatorname{Pd}(110)$ exhibit a strong dependence of their electronic and structural properties on the annealing temperature. Deposition of $\mathrm{Au}$ at $150 \mathrm{~K}$ leads to rather rough surfaces, especially on $\mathrm{Pt}$, whereas on $\mathrm{Pd}$ the roughness seems to be more or less limited to the topmost atomic layer. In all cases the formation of a surface alloy with increasing temperature is observed. Due to the different mixing properties of $\mathrm{Au}$ with $\mathrm{Pt}$ and with $\mathrm{Pd}$, the resulting alloys differ considerably in their formation temperature as well as in their morphology and electronic structure. For the formation of an Au-Pt surface alloy an annealing temperature of $950 \mathrm{~K}$ is necessary, whereas an $\mathrm{Au}-\mathrm{Pd}$ surface alloy, at least on the (110) orientated surface, is already detectable at $650 \mathrm{~K}$. The existence of an alloy on the topmost atomic layer of the (111) orientated Pd substrate cannot be clearly evidenced by our adsorption experiments, although it seems to be very probable considering the UPS data. The onset of the Au diffusion into the substrate bulk takes place at the interface already at $750 \mathrm{~K}$ on $\mathrm{Pt}$ and at $450 \mathrm{~K}$ on $\mathrm{Pd}$, respectively. The complete $\mathrm{Au}$ depletion from the surface is reached after annealing the samples to 
$1150 \mathrm{~K}(\mathrm{Pt})$ and $1050 \mathrm{~K}(\mathrm{Pd})$, respectively. Furthermore, the surface orientation has an influence on the electronic structure of the ordered $\mathrm{Au}$ films annealed to medium temperatures. Au films on (111) orientated surfaces exhibit a bulk-like center-of-gravity peak in the $\mathrm{He}(\mathrm{II})$ excited UPS spectra, which is not the case on the (110) orientated Pd sample.

We have shown that the combination of PAX and UPS can provide detailed information on the formation of surface alloys from metallic overlayers. The different information depth of these two techniques allows a distinction of the surface and the interface region. The use of $\mathrm{CO}$ as a probe molecule in UPS measurements can yield even further information, which complement the PAX and UPS results.

\section{Acknowledgments}

T. Kobiela and A. Krupski express their appreciation to the Alexander von Humboldt foundation for financing their research stays in Germany.

\section{References}

[1] R.M. Lambert, in: Chemisorption and Reactivity on Supported Clusters and Thin Films, Eds. R.M. Lambert, G. Pacchioni, Kluwer, Dordrecht 1997, p. 1.

[2] J. Zhang, K. Saski, E. Sutter, R.R. Adzic, Science 315, 220 (2007).

[3] B. Hammer, J.K. Nørskov, Nature 376, 238 (1995).

[4] R. Meyer, C. Lemire, S.K. Shaikhutdinov, H.-J. Freund, Gold Bulletin 37, 72 (2004).

[5] S. Ichikawa, T. Akita, M. Okumura, M. Koyhyama, K. Tanaka, JEOL News 38, 6 (2003).

[6] C. Breinlich, J. Haubrich, C. Becker, A. Valcárcel, F. Delbecq, K. Wandelt, J. Catalysis 251, 123 (2007).

[7] K. Wandelt, Appl. Surf. Sci. 111, 1 (1997).

[8] A. Jablonski, K. Wandelt, Surf. Interface Anal. 17, 611 (1991).

[9] A. Jablonski, S. Eder, K. Wandelt, Appl. Surf. Sci. 22/23, 309 (1985).

[10] K. Wandelt, K. Markert, P. Dolle, A. Jablonski, J.W. Niemantsverdriet, Surf. Interface Anal. 12, 15 (1988).

[11] M. Alnot, V. Gorodetskii, A. Cassuto, J.J. Ehrhardt, Surf. Sci. 162, 886 (1985).

[12] J.A. Barnard, J.J. Ehrhardt, H. Azzouizi, M. Alnot, Surf. Sci. 211/212, 714 (1989).

[13] G. Schönhense, A. Eyers, U. Friess, F. Schäfers, U. Heinzmann, Phys. Rev. Lett. $\mathbf{5 4}, 547$ (1985).

[14] J. Küppers, K. Wandelt, G. Ertl, Phys. Rev. Lett. 43, 928 (1979).

[15] G.R. Castro, H. Isern, U. Schneider, M. Stöcker, K. Wandelt, Vacuum 41, 393 (1990).

[16] J. Hulse, J. Küppers, K. Wandelt, G. Ertl, Appl. Surf. Sci. 6, 453 (1980).

[17] T. Berghaus, C. Lunau, H. Neddermayer, V. Rogge, Surf. Sci. 182, 13 (1987). 
[18] D. Fargues, J.J. Ehrhardt, M. Abon, J.C. Bertolini, Surf. Sci. 194, 149 (1988).

[19] M. Salmeron, S. Ferrer, M. Jazzar, G.A. Somorjai, Phys. Rev. B 28, 6758 (1983).

[20] T. Kobiela, M. Moors, W. Linhart, I. Cebula, A. Krupski, C. Becker, K. Wandelt, in preparation.

[21] M. Moors, T. Kobiela, M. Kralj, T. Pertram, C. Becker, K. Wandelt, in preparation.

[22] P.H. Citrin, G.K. Wertheim, Phys. Rev. Lett. 41, 1425 (1978).

[23] H. Brune, S. Bales, J. Jacobsen, C. Boragno, K. Kern, Phys. Rev. B 60, 5991 (1999).

[24] P.W. Davies, M.A. Quinlan, G.A. Samorjai, Surf. Sci. 121, 290 (1982).

[25] I.A. Abrikosov, H.L. Skriver, Phys. Rev. B 47, 16532 (1993).

[26] B.J. Waclawski, J.F. Herbst, Phys. Rev. Lett. 35, 1594 (1975).

[27] A. Cassuto, J.J. Ehrhardt, J. Phys. (France) 19, 1753 (1988).

[28] R.P. Elliot, F.A. Shunk, Bull. Alloy Phase Diagrams 2, 482 (1982).

[29] S. Takizawa, K. Terakura, Phys. Rev. B 39, 5792 (1989).

[30] M. Kralj, A. Bailly, M.-C. Saint-Lager, S. Degen, A. Krupski, C. Becker, P. Dolle, M. De Santis, K. Wandelt, Surf. Sci. 600, 2614 (2006).

[31] K. Wandelt, J.E. Hulse, J. Chem. Phys. 80, 1340 (1984).

[32] M. Milun, P. Pervan, K. Wandelt, Surf. Sci. 218, 363 (1989).

[33] J.-W. He, P.R. Norton, J. Chem. Phys. 89, 1170 (1988).

[34] M. Mavrikakis, P. Stoltze, J. Nørskov, Catal. Lett. 64, 10 (2000).

[35] S.R. Bahn, N. Lopez, J. Nørskov, K.W. Jacobsen, Phys. Rev. B 66, 081405(R) (2002).

[36] J. Küppers, H. Conrad, G. Ertl, E.E. Latta, Jpn. J. Appl. Phys. Suppl. 2-2, 225 (1974). 